\title{
Biochemical and Immunological Comparison of Aliphatic Amidases Produced by Pseudomonas Species
}

\author{
By PATRICIA H. CLARKE \\ Department of Biochemistry, University College London, \\ Gower Street, London, WCIE 6BT
}

(Accepted for publication 26 January 1972)

\begin{abstract}
SUMMARY
Strains of Pseudomonas aeruginosa, $P$. putida, $P$. acidovorans and $P$. cepacia were tested for growth on minimal salt media containing aliphatic amides. All strains of $P$. aeruginosa, $P$. acidovorans, $P$. cepacia and some strains of $P$. putida biotype A grew on acetamide; some strains of $P$. putida and $P$. acidovorans also grew on butyramide. The inducible aliphatic amidases had both hydrolase and transferase activities and were similar in substrate specificities. All species hydrolysed propionamide more rapidly than acetamide while acetamide was the best substrate for the transferase reaction. The rate of butyramide hydrolysis was 2 to $3 \%$ of the rate of acetamide hydrolysis for all species including those strains able to grow on butyramide. The amidases of $P$. putida A87 and $P$. acidovorans $\mathrm{I} 4$ were inducible by butyramide. Cell-free extracts of $P$. aeruginosa strains induced with acetamide cross-reacted completely with antiserum prepared against purified $P$. aeruginosa amidase A. Partial cross-reactions occurred with P. putida and P. acidovorans amidases and a very weak cross-reaction with $P$. cepacia amidase.
\end{abstract}

\section{INTRODUCTION}

Kelly \& Clarke (1960) showed that a strain of Pseudomonas aeruginosa growing on acetamide as the sole source of carbon and nitrogen possessed an inducible aliphatic amidase. This enzyme had very limited inducer and substrate specificities and acetamide and propionamide were the only aliphatic amides which could support growth. Buhlman, Vischer \& Bruhin (I96I) found that among the fluorescent pseudomonads only those strains which could be classed as $P$. aeruginosa were able to produce an alkaline reaction in glucose + acetamide medium and this reaction was presumably due to the activity of similar aliphatic amidases. Jakoby \& Fredericks (1964) isolated a fluorescent pseudomonad which grew in a minimal salts medium with acetamide as the carbon source. This strain produced an amidase with properties similar to those reported for the $P$. aeruginosa enzyme (Kelly \& Clarke, I962; Brammar \& Clarke, I964; Kelly \& Kornberg, 1964). In their survey of the pseudomonads, Stanier, Palleroni \& Doudoroff (1966) reported that all the strains of $P$. aeruginosa which they examined were able to grow on acetamide. In addition, some strains of $P$. putida biotype A, P.acidovorans and $P$. cepacia ( $P$. multivorans) were also able to grow on acetamide.

There is considerable homology among some of the enzymes of Pseudomonas species. Queener \& Gunsalus (1970) showed that anthranilate synthase from extracts of Pseudomonas aeruginosa, P. putida, P. acidovorans, P.testosteroni, P. stutzeri and P. cepacia could be separated into two subunits and that these subunits could be associated to form hybrid enzymes. The hybrid enzymes made from $P$. aeruginos $a$ and $P$. putida (group a-p) subunits, or 
from $P$. acidovorans and $P$. testosteroni (group $\mathrm{c}-\mathrm{t}$ ) subunits, were fully active, whereas hybrid enzymes made with one subunit from each group had lower activities than the native enzymes.

Stanier (I968) compared the pathways employed for the catabolism of aromatic compounds and pointed out that the pseudomonads could be divided into two distinct groups. Pseudomonas aeruginosa, $P$. putida, $P$. stutzeri and $P$. cepacia all metabolize benzoate and $p-\mathrm{OH}$ benzoate via the $\beta$-ketoadipate pathway while $P$. acidovorans and $P$. testosteroni utilize the $\alpha$-ketoacid pathway. However, there are differences in detail in the enzymes involved (Kemp $\&$ Hegeman, I968). Two of the enzymes of the catechol branch of the $\beta$-ketoadipate pathway were tested for structural homology by examining the immunological cross-reactions to antisera prepared against the muconate-lactonizing enzyme and the muconolactone isomerase purified from $P$. putida (Ornston, 1966). Extracts of all strains of $P$. putida gave crossreactions with the antiserum to the enzymes purified from $P$. putida A90 indicating almost complete homology. Extracts of strains of $P$. aeruginosa gave strong cross-reactions but the marked spurring with the $P$. putida enzymes indicated only partial homology between the enzymes from these two species. Weaker cross reactions were observed with some strains of $P$. fluorescens and $P$. stutzeri and no cross-reactions were detected with $P$. cepacia strains.

We have examined the growth of strains of Pseudomonas aeruginosa, P. putida, $P$. acidovorans and $P$. cepacia on several aliphatic amides and tested the amidase substrate and inducer specificities. Cell-free extracts were examined by starch gel electrophoresis and tested for immunological cross-reactions with antiserum prepared against a purified preparation of $P$. aeruginosa amidase from a constitutive mutant of strain PACI used in our previous studies. We have isolated a number of mutants with altered substrate and inducer specificities (Brown, Brown \& Clarke, 1969; Brown \& Clarke, 1972) which can grow on amides not available to the wild-type strain. The properties of the aliphatic amidases produced by the four different Pseudomonas species were compared with those of the mutant P. aeruginosa strains.

\section{METHODS}

Bacterial strains. The strains used are listed in Table I. Professor R. Y. Stanier kindly provided representative strains belonging to each of the species tested. We have recently renumbered the Pseudomonas aeruginosa strains in our collection in accordance with the proposals of Demerec, Adelberg, Clark \& Hartman (1966) in a similar way to the other collections of Pseudomonas strains used for genetic studies (Holloway, 1969). The old numbers used in previous publications are given in brackets. In addition, we have designated the amidase produced by the wild-type $P$. aeruginosa $\mathrm{PACI}$ as amidase $\mathrm{A}$ and mutant amidase proteins are assigned letters according to the new substrate activity, e.g. amidase $B$ is produced by certain butyramide-utilizing mutants (Brown et al. 1969).

Media. Cultures were maintained on nutrient agar slopes. Minimal salt medium (Brammar \& Clarke, 1964) was used for all growth experiments, with the addition of various compounds as carbon and nitrogen sources. Succinate, pyruvate and lactate as sodium salts were added before autoclaving; amides were sterilized by filtration and added aseptically to the minimal salt medium. Solid media contained $\mathrm{I} \cdot 0 \%(\mathrm{w} / \mathrm{v})$ Oxoid agar no. $\mathrm{I}$. The composition of the amide selective media with respect to carbon and nitrogen sources was as follows $(\%, \mathrm{w} / \mathrm{v})$ : AM, acetamide $0.5+\left(\mathrm{NH}_{4}\right)_{2} \mathrm{SO}_{4} 0 . \mathrm{I} ; \mathrm{B}$, butyramide $0 . \mathrm{I}+\left(\mathrm{NH}_{4}\right)_{2} \mathrm{SO}_{4} \mathrm{O} \cdot \mathrm{I} ; \mathrm{S} / \mathrm{F}$, succinate $\mathrm{I} \cdot \mathrm{O}+$ formamide $0 \cdot \mathrm{I} ; \mathrm{S} / \mathrm{L}$, succinate $\mathrm{I} \cdot \mathrm{O}+$ lactamide $0 \cdot 02$.

Growth. Cultures were grown in $5 \mathrm{ml}$ medium in $25 \mathrm{ml}$ screw-cap bottles, or as larger volumes in conical flasks of capacity five or ten times the media volume. Experiments on 
rates of enzyme synthesis during exponential growth were carried out by inoculating Ioo to $150 \mathrm{ml}$ of the appropriate medium with a tenth of its volume of an overnight culture in the same medium. Samples were removed at intervals to determine bacterial growth and amidase activity. When several compounds were to be tested for their inductive or repressive effects, the exponentially growing culture was divided between an appropriate number of flasks. For some experiments, side-arm flasks (100 ml, with Io $\mathrm{ml}$ EEL colorimeter tubes attached) were inoculated in parallel. All experiments on rates of enzyme induction were carried out at $30^{\circ} \mathrm{C}$.

Measurement of bacterial growth. Bacterial growth was estimated by measuring the extinction at $670 \mathrm{~nm}$ in a Unicam SP 600 spectrophotometer and converting the reading to dry weight of bacteria $/ \mathrm{ml}$ by reference to a standard curve determined for Pseudomonas aeruginosa PACı. It was assumed that differences in the relationships of dry $\mathrm{wt} / \mathrm{ml}$ to optical density of the different Pseudomonas cultures could be ignored since relative rather than absolute values were required. The readings obtained with the EEL colorimeter using a green filter OGR I were treated similarly.

Preparation of cell-free extracts. Bacteria were grown overnight in I I acetamide medium in 51 conical flasks, except for strains of Pseudomonas acidovorans which were grown for two to three days. Pseudomonas aeruginosa strains were grown at $37^{\circ} \mathrm{C}$ and the other species at $30^{\circ} \mathrm{C}$. Constitutive mutants and control cultures were grown in succinate medium. Bacteria were harvested and resuspended in tris buffer $\mathrm{O} \cdot \mathrm{I} \mathrm{M}, \mathrm{pH} 7 \cdot 2$, disrupted by passage through a French pressure cell, and stored at $4{ }^{\circ} \mathrm{C}$ or frozen.

Enzyme assays. Routine assays were made by the transferase reaction with acetamide as substrate. One unit of amidase activity is defined as the amount of enzyme catalysing the formation of I $\mu \mathrm{mol}$ acethydroxamate under the standard assay conditions. The substrate mixture consisted of I part acetamide $0.4 \mathrm{M}$, I part freshly neutralized hydroxylamine hydrochloride $2 \mathrm{M}$, and 2 parts tris buffer $0 \cdot \mathrm{I} \mathrm{M}, \mathrm{pH} 7 \cdot 2$. The stock hydroxylamine hydrochloride solution was $5 \mathrm{M}$ and was neutralized and diluted as required. The neutralized hydroxylamine and the substrate mixture were kept on ice and made up freshly for each batch of assays. For the standard assay $0.1 \mathrm{ml}$ sample was added to $0.9 \mathrm{ml}$ substrate mixture equilibrated at $37^{\circ} \mathrm{C}$, incubated for Io min and the reaction stopped by adding $2 \mathrm{ml}$ ferric chloride solution ( $100 \mathrm{ml} \mathrm{FeCl}_{3} 60 \%$, w/v, (Analar) $+57 \mathrm{ml} \mathrm{HCl}$ (Analar), made up to I 1 with distilled water). Samples were diluted as necessary to give assay values of 0.2 to 0.7 when read at $500 \mathrm{~nm}$ with an SP 600 spectrophotometer against a substrate blank incubated for the same period as the sample assay. For some experiments the sample size or incubation time was increased. Final concentrations of other amides were propionamide $0 . \mathrm{I} M$, butyramide $0.125 \mathrm{M}$. In comparisons of substrate specificities assays were carried out for periods up to $20 \mathrm{~min}$ to check that the reactions were linear with time. Hydrolase assays were carried out by estimating the ammonia produced by the Conway microdiffusion method as described by Kelly \& Clarke (1962).

A microassay was devised for qualitative assay of amidase production by cultures growing on agar plates, in particular for the identification of constitutive mutants. Cultures were grown on succinate agar plates and either a single colony, or the growth from a small area of a patch plate, was scraped off with a loop and suspended in $0.1 \mathrm{ml}$ of tris buffer $(\mathrm{pH} 7.2$ $0.1 \mathrm{M}$ ). A $0.2 \mathrm{ml}$ sample of the amide substrate mixture was added and after $30 \mathrm{~min}$ incubation at room temperature the reaction was stopped by the addition of $0.4 \mathrm{ml}$ ferric chloride. Amidase-positive cultures gave a deep red-black colour.

Starch gel electrophoresis. Starch gel electrophoresis was performed as described by Gammack, Huehns, Shooter \& Gerald (1960) with the discontinuous tris + citrate + borate 
buffer system at $\mathrm{pH} 8 \cdot 5$. Gels were sliced and one slice was stained for protein with a saturated solution of naphthalene black in methanol + water + acetic acid $(5+5+\mathrm{I}$, by vol) for $5 \mathrm{~min}$. The background stain was washed out with the same solvent. The second gel slice was stained for amidase hydrolase activity by overlaying with a filter paper soaked in acetamide, incubating for $\mathrm{I} 5 \mathrm{~min}$ at $37^{\circ} \mathrm{C}$ and replacing with one soaked in Nessler's reagent; for transferase activity by overlaying with a filter paper soaked in the acetamide-hydroxylamine-tris buffer mixture and replacing with a paper soaked in the ferric chloride reagent. The position of the amidase in each case was shown by the formation of a brown band on both the gel and the paper.

Immunodiffusion. Antiserum ( $10 \mu \mathrm{l}$ ) prepared against Pseudomonas aeruginosa A amidase (Brown et al. 1969) was placed in the centre well of a gel prepared on a microscope slide ( $2 \mathrm{ml} \mathrm{I} \%$, w/v, Difco agar Noble in barbitone + acetate buffer). The wells were cut with a no. I cork borer; the outer wells contained io $\mu \mathrm{l}$ samples of cell-free extracts for all extracts except those from $P$. cepacia for which $20 \mu \mathrm{l}$ and $30 \mu \mathrm{l}$ samples were used. The reactions developed after about $24 \mathrm{~h}$ at room temperature in a damp atmosphere.

\section{RESULTS}

\section{Growth on aliphatic amides}

Minimal salt agar containing various amides has been used to select structural and regulator gene mutants of Pseudomonas aeruginosa (Clarke, 1970). Table I lists the growth characteristics of some of the mutants which have been isolated and compares them with the wild-type isolates of Pseudomonas species reported to be able to grow on acetamide.

The wild-type strain PACI grows well on acetamide (AM) plates but amidase-negative mutants and some of the mutants producing altered enzymes are unable to do so. Constitutive mutants (PACIII, PACI28, PAC35I) are able to grow on succinate +formamide (S/F) plates but the wild-type is unable to do so since formamide is a poor substrate and very poor inducer. Some inducible mutants were isolated on S/F plates (e.g. PACI52) and these were shown to have altered inducer specificity being readily induced by formamide (Brammar, Clarke \& Skinner, 1967). Some constitutive mutants, e.g. PACI I I, were unable to grow on butyramide (B) plates because amidase synthesis in these strains was severely repressed by butyramide. Other constitutive mutants, e.g. PACI 28, grew readily on B plates because they were resistant to butyramide repression and produced large amounts of the wild-type A amidase which has low but significant activity towards butyramide (Brown \& Clarke, 1970). The constitutive mutant PACI I I was the parent of strain PAC35 I which produced the altered B amidase with a much higher activity for butyramide as substrate than the wild-type A enzyme (Brown et al. 1969). The succinate+lactamide (S/L) plates were used to isolate mutants which were resistant to catabolite repression; lactamide is a very good inducer but a poor substrate so that a high amidase concentration per bacterial cell is required for growth in a medium in which succinate is the major carbon source $(\mathrm{I} \%, \mathrm{w} / \mathrm{v})$, and lactamide at a low concentration $(0.02 \%, \mathrm{w} / \mathrm{v})$ provides the nitrogen source. Strain PACI 43 was inducible, produced the wild-type A amidase and was less sensitive than the wild type to repression by succinate (Clarke, Houldsworth \& Lilly, 1968). Strain PAC35 I grew on S/L plates because it produced the $\mathrm{B}$ enzyme which has a much higher activity than the A enzyme for lactamide as well as for butyramide. The growth phenotypes on these selective amide media may therefore result from different classes of genetic mutations.

All the strains of Pseudomonas aeruginosa grew well on acetamide plates at $37^{\circ} \mathrm{C}$. Their growth pattern was identical to that of strain PACI ; they were unable to grow on butyra- 
Table I. Growth of Pseudomonas spp. on aliphatic amides

Growth estimated visually after 3 days. Pseudomonas aeruginosa grown at $37{ }^{\circ} \mathrm{C}$, other species at $30^{\circ} \mathrm{C}$. Plates inoculated by spreading $0.1 \mathrm{ml}$ of a suitable dilution to give about 50 colonies per plate.

Strain no.

Origin and description

Pseudomonas aerus
PACI $(8602)$
PACI I (CI )
PACI 28 (CB4)
PACI 43 (LII)
PACI 52 (F5)
PAC35I (B6)
PAOI
45
52
I32
277
278
416
277 CI
ATCC 7700
P. putida
A43
A5I
A56
A76
A87
AI45
AI 54
A87CI
A90

$\boldsymbol{P}$. acidovorans

I4

61

105

114

NCIB 968r

P. testosteroni

NCIB 9682

NCIB 9683

P. cepacia

714

716

727

738

744

Wild-type (Kelly \& Clarke, 1960) Received from A. H. Fensom by Stanier et al. 1966) by Stanier et al. 1966)
Minimal salt agar with amides

\begin{tabular}{cccc}
\hline AM & B & S/F & S/L \\
& & & \\
+++ & - & tr & tr \\
+++ & & +++ & tr \\
+++ & +++ & +++ & - \\
+++ & - & tr & ++ \\
+++ & - & +++ & tr \\
+++ & +++ & +++ & ++ \\
+++ & - & tr & tr \\
+++ & - & tr & tr \\
+++ & - & tr & tr \\
+++ & - & tr & tr \\
+++ & - & tr & tr \\
+++ & - & tr & tr \\
+++ & - & tr & tr \\
+++ & - & +++ & tr \\
+++ & - & tr & tr \\
& & & \\
+++ & tr & + & + \\
+++ & tr & + & + \\
+++ & tr & + & + \\
+++ & - & + & + \\
+++ & ++ & + & + \\
+++ & - & + & + \\
+++ & ++ & + & + \\
+++ & ++ & +++ & + \\
- & - & - & -
\end{tabular}

Received from R. Y. Stanier (Stanier et al. 1966) Received from R. Y. Stanier (Stanier et al. I966) Received from R. Y. Stanier (Stanier et al. 1966) Received from R. Y. Stanier (Stanier et al. 1966) Received from R. Y. Stanier (Stanier et al. I966) Received from R. Y. Stanier (Stanier et al. 1966) Received from R. Y. Stanier (Stanier et al. 1966) Constitutive, isolated from $\mathrm{A} 87$ on $\mathrm{S} / \mathrm{F}$ medium Also A6, A7, A49, AI I 5, AI30 (Stanier et al. 1966)

(Brammar et al. Inducible, A amidase (Clarke et al. I 968) Inducible, A amidase (Brammar et al. I967) Constitutive, B amidase (Brown et al. 1969) Received from B. W. Holloway (Holloway, 1969) Received from R. Y. Stanier (Stanier et al. 1966) Received from R. Y. Stanier (Stanier et al. 1966) Received from R. Y. Stanier (Stanier et al. I966) Received from R. Y. Stanier (Stanier et al. 1966) Received from R. Y. Stanier (Stanier et al. 1966) Constitutive, isolated from 277 on $\mathrm{S} / \mathrm{F}$ medium

Received from R. Y. Stanier (Stanier et al. 1966) Received from R. Y. Stanier (Stanier et al. I966) Received from R. Y. Stanier (Stanier et al. I 966) Received from R. Y. Stanier (Stanier et al. 1966) Received from NCIB (Same original culture as I4)

Received from NCIB (assigned to $P$. testosteroni

Received from NCIB (assigned to $P$. testosteroni

Received from R. Y. Stanier (Ballard et al. 1970) Received from R. Y. Stanier (Ballard et al. I970)

Received from R. Y. Stanier (Ballard et al. 1970)

Received from R. Y. Stanier (Ballard et al. 1970) Received from R. Y. Stanier (Ballard et al. 1970)
$++$

$$
++
$$$$
++
$$$$
+
$$$$
+\quad+
$$

$+$

$+$

$\begin{array}{cc}- & +t \\ +t & +t\end{array}$

$\begin{array}{cc}- & +t \\ +t & +t\end{array}$

$$
\begin{aligned}
& \operatorname{tr} \\
& \operatorname{tr} \\
& \operatorname{tr} \\
& \operatorname{tr} \\
& \operatorname{tr}
\end{aligned}
$$

$\begin{array}{llll}+++ & - & ++ & ++ \\ +++ & - & ++ & ++ \\ +++ & - & ++ & ++ \\ +++ & - & ++ & ++ \\ +++ & - & ++ & ++\end{array}$

$+++,++,+, \operatorname{tr},-=$ Growth range from large raised colonies to no visible growth; $\mathrm{AM}=$ acetamide $0.5 \%(\mathrm{w} / \mathrm{v}) ; \mathrm{B}=$ butyramide $0 . \mathrm{I} \%(\mathrm{w} / \mathrm{v}) ; \mathrm{S} / \mathrm{F}=$ succinate $\mathrm{I} \%(\mathrm{w} / \mathrm{v})+$ formamide $0 . \mathrm{I} \%(\mathrm{w} / \mathrm{v}) ; \mathrm{S} / \mathrm{L}=$ succinate $I \%(w / v)+$ lactamide $0.02 \%(w / v)$.

mide and produced only trace growth on S/F and S/L plates. Strain 277 was selected for isolation of constitutive mutants. An inoculum of $10^{8}$ bacteria was spread on $\mathrm{S} / \mathrm{F}$ plates and constitutive mutants appeared spontaneously after 4 to 5 days of incubation. Constitutive mutants were isolated in a similar manner from strain PAOr; and the methods used with the 
PAC strains were also successful in isolating catabolite repression-resistant and butyramideutilizing mutants of PAO strains.

The growth of Pseudomonas putida strains on the selective media was more variable. Stanier et al. (1966) reported that one strain of $P$. putida biotype B was able to grow on acetamide but they have now confirmed our finding that it is acetamide-negative. All the strains of $P$. putida biotype A which they had listed as acetamide-positive grew well on our acetamide medium and their negative strains were unable to do so. Growth on S/F plates of the acetamide-positive strains was somewhat greater than that of the P. aeruginosa strains but was still sufficiently weak to allow selection of constitutive mutants which appeared spontaneously as large colonies after 5 to 6 days of incubation at $30^{\circ} \mathrm{C}$. Growth of these strains on $\mathrm{S} / \mathrm{L}$ plates was significantly greater than for the $P$. aeruginosa strains. On butyramide plates the results were rather variable, some strains produced a reasonable amount of growth after two days, others grew after five days and some did not grow at all.

Stanier et al. (1966) divided the acidovorans group into two species, Pseudomonas acidovorans and $P$. testosteroni. From our point of view, the interesting finding was that all $P$. acidovorans strains and none of the $P$. testosteroni strains grew on acetamide. Four strains of $P$. acidovorans from Stanier's collection grew on our acetamide medium. Strain I4 was listed as strain 7 of den Dooren de Jong (Stanier et al. I966) and the NCIB strain 968 I was also assigned this provenance. These two cultures behaved in an identical way in our tests, with the exception that strain I4 grew more slowly on all media than strain NCIB 968r. Growth of all four cultures on S/F plates was greater than that observed for $P$. aeruginosa and $P$. putida and this medium could not be used for the isolation of constitutive mutants. These strains also grew on butyramide, but grew less well on $\mathrm{S} / \mathrm{L}$ plates than did the P. putida strains. Two strains of $P$. testosteroni were unable to grow on any of the amide media.

Most of the strains assigned by Stanier et al. (1966) to the species Pseudomonas multivorans were found to utilize acetamide. Subsequently, it was shown that this group could not be distinguished from the plant pathogenic species $P$. cepacia and the latter name had priority of nomenclature (Ballard, Palleroni, Doudoroff \& Stanier, 1970). The five strains tested all grew vigorously on acetamide and grew fairly well on $\mathrm{S} / \mathrm{F}$ and $\mathrm{S} / \mathrm{L}$ plates, but none grew on butyramide.

The amide selective media used in these tests were devised especially for working with mutants of PAC strains. These simple growth tests showed that they gave clear-cut results with other strains of Pseudomonas aeruginosa and could be used equally well for isolation of mutant strains. The different growth response of $P$. putida, $P$. acidovorans and $P$. cepacia suggested that the species might differ among themselves in the properties of the amidases and the regulatory systems controlling amidase synthesis.

\section{Pseudomonas aeruginosa amidase}

None of the strains produced amidase in succinate medium but all did so in acetamide medium. Cultures were grown overnight in minimal salt medium containing $0.5 \%(\mathrm{w} / \mathrm{v})$ acetamide and Table 2 gives the values obtained for dry $\mathrm{wt} / \mathrm{ml}$ of bacteria and the amidase specific activity. There is always some variation in the specific activities of cultures of the wild type PACI grown overnight in acetamide medium and the values obtained for the other Pseudomonas aeruginosa strains compare reasonably well with PACI with the exception of strain I 32 which gave a rather low value.

The cultures were harvested, disrupted with the French press and, after removal of the debris, the cell-free extracts were examined by starch gel electrophoresis and immunodiffusion on agar gels. The starch gels were cut into two slices, one of which was stained for 
Table 2. Amidases produced in acetamide minimal salt medium

\begin{tabular}{|c|c|c|c|}
\hline Strain no. & $\begin{array}{c}\text { Bacteria } \\
\mathrm{mg} \text { dry wt } / \mathrm{ml}\end{array}$ & $\begin{array}{c}\text { Acyltransferase activity } \\
\mu \text { mol acethydroxamate } / \mathrm{ml} \mathrm{a}\end{array}$ & $\begin{array}{r}\text { Specific acti } \\
\text { amidase units } / \mathrm{n}\end{array}$ \\
\hline \multicolumn{4}{|c|}{$P_{\text {seudomonas aeruginosa }}$} \\
\hline PACI & 0.95 & 15.8 & $16 \cdot 5$ \\
\hline 45 & I. 2 & 17 & 14 \\
\hline 52 & 0.93 & $6 \cdot 8$ & $7 \cdot 2$ \\
\hline 132 & 1.05 & $2 \cdot 5$ & $2 \cdot 3$ \\
\hline 277 & $1 \cdot 09$ & 13.9 & $12 \cdot 7$ \\
\hline 278 & 1.09 & $17 \cdot 6$ & $16 \cdot 1$ \\
\hline 416 & 0.92 & $8 \cdot 7$ & $9 \cdot 4$ \\
\hline \multicolumn{4}{|l|}{$P$. putida } \\
\hline A43 & $1 \cdot 01$ & $10 \cdot 0$ & $10 \cdot 1$ \\
\hline A51 & 0.73 & $6 \cdot 1$ & $8 \cdot 4$ \\
\hline A56 & $1 \cdot 22$ & $20 \cdot 3$ & $16 \cdot 6$ \\
\hline A 76 & 0.98 & $7 \cdot 4$ & $7 \cdot 5$ \\
\hline A87 & 0.98 & 13 & $13 \cdot 2$ \\
\hline AI 45 & I. 02 & $4 \cdot 1$ & 4.0 \\
\hline A1 54 & 1.25 & $8 \cdot 5$ & $6 \cdot 8$ \\
\hline \multicolumn{4}{|l|}{ P. acidovorans } \\
\hline NCIB 968I & 0.81 & $10 \cdot 3$ & $12 \cdot 7$ \\
\hline \multicolumn{4}{|l|}{ P. cepacia } \\
\hline 716 & 0.82 & 3.5 & $4 \cdot 3$ \\
\hline
\end{tabular}

protein and the other for amidase transferase activity with acetamide as substrate. In all the extracts the overall protein pattern was identical, the amidase forming a major protein band and the amidases from all the Pseudomonas aeruginosa strains having the same electrophoretic mobility. In the immunodiffusion tests there were strong precipitin reactions between the amidases in the cell-free extracts of all the $P$. aeruginosa strains with the antiserum to the purified PAC amidase $\mathrm{A}$ and there appeared to be complete homology among the P. aeruginosa amidases (Fig. I). These observations suggested that there was very little strain variation in the physicochemical properties of the $P$. aeruginosa amidases.

Strain 277 was examined in more detail for inducer and substrate specificities. The rates of amidase induction were measured with cultures growing exponentially in succinate medium and induced with Io mM-formamide, acetamide or propionamide. There was no induction with butyramide and the induction ratio for the three inducing amides was similar to that for strain PACI (Table 3). A washed suspension of an acetamide-grown culture of 277 was used to assay amidase hydrolase and transferase activities. For the transferase reaction the rates for acetamide:proprionamide were in the ratio $100: 23$ which was similar to that previously obtained for the PACI amidase A (Brown et al. 1969). The relative rates of amide hydrolysis, determined by the Conway method, were also similar to those for PAC amidase A (Table 4). These results suggested that the amidases produced by Pseudomonas aeruginosa strains were alike with respect to amidase structure, properties and regulation of synthesis.

\section{Pseudomonas putida amidase}

The amidases produced by the acetamide-positive Pseudomonas putida strains were also inducible for all strains tested. Table 2 shows that the amounts of bacteria and the amidase specific activities obtained after overnight growth in acetamide medium were similar to those for the $P$. aeruginosa strains. Thus, for acetamide as a growth substrate the amidases of both 

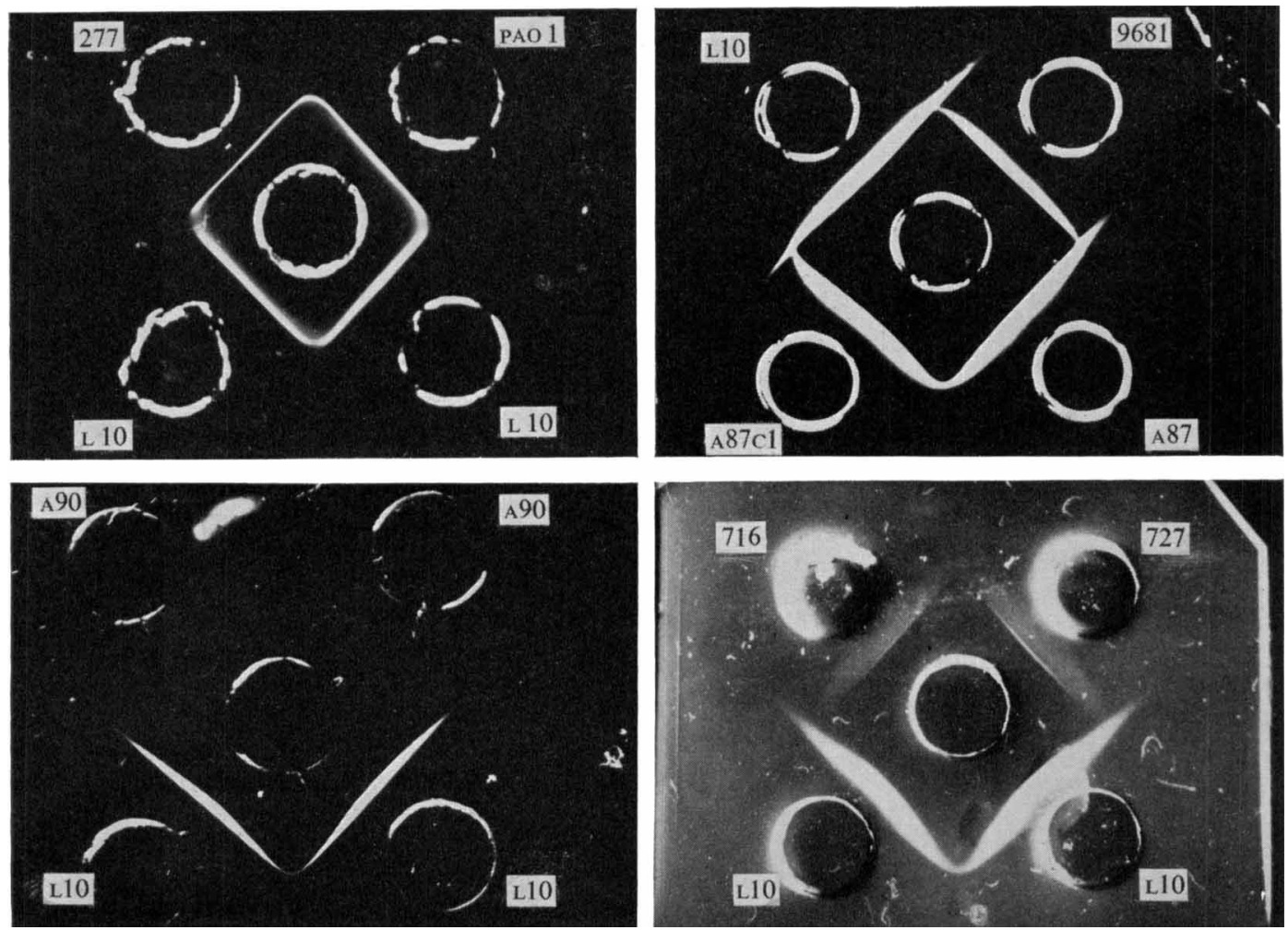

Fig. I. Immunodiffusion reactions in agar gels. The centre wells all contain antiserum prepared against Pseudomonas aeruginosa amidase A purified from strain PACI42 (LIO). (a) Extracts from Pseudomonas aeruginosa strains PAOI and 277 grown in acetamide medium and the constitutive mutant PACI42 (LIO) grown in succinate medium. (b) Extracts from Pseudomonas putida A87 and $P$. acidovorans NCIB 968I grown in acetamide medium and constitutive mutants of $P$. aeruginosa PACI42 (L1O) and $P$. putida A87 grown in succinate medium. (c) Extracts from $P$ seudomonas putida A90 grown in lactate medium + Io mM-lactamide and $P$. aeruginosa PACI42 (LIO) grown in succinate medium. (d) Extracts from Pseudomonas cepacia strains 716 and 727 grown in acetamide medium and $P$. aeruginosa PACI 42 (LIO) grown in succinate medium.

Table 3. Amidase induction in Pseudomonas aeruginosa and P. putida strains by formamide, acetamide, propionamide and butyramide in succinate medium

\begin{tabular}{lcccc}
\multicolumn{5}{c}{ Rates of amidase induction* } \\
Strain no. & Formamide & Acetamide & Propionamide & Butyramide \\
$\begin{array}{l}\text { Pseudomonas aeruginosa } \\
\text { PACI }\end{array}$ & 7 & 100 & 50 & $<2$ \\
PACI52 & 37 & 100 & 68 & - \\
277 & 7 & 100 & 40 & $<2$ \\
$\begin{array}{l}\text { P.putida } \\
\text { A87 }\end{array}$ & 37 & 100 & 47 & $<2$
\end{tabular}

* Rates of amidase induction are expressed relative to that for acetamide assigned an arbitrary value of 100 .

$-=$ Not measured. 


\title{
Host-controlled Modification and Restriction of Phages in Coagulase-negative Staphylococci
}

\author{
By J. VERHOEF, ${ }^{*}$ C. P. A. VAN BOVEN AND BERNARDA \\ HOLTRIGTER \\ Laboratory of Microbiology, University of Utrecht, \\ Utrecht, The Netherlands
}

(Accepted for publication 25 January 1972)

SUMMAR Y

Three host-controlled modification and restriction systems occurring among coagulase-negative staphylococci belonging to the Staphylococcus subgroup II are described. The phage patterns, observed by typing the staphylococci with a provisional typing set of eighteen phages, are mainly determined by these host specificity systems. A strain, which was not restrictive to the phages, did not become restrictive after lysogenization with any of the eighteen phages.

Infection of a restricting host with ${ }^{3} \mathrm{H}$-labelled phages was followed by a rapid breakdown of phage DNA, as demonstrated by the appearance of radioactive label in the cold-acid-soluble DNA fraction of extracted adsorption mixtures.

\section{INTRODUCTION}

Recently a provisional phage typing system for Staphylococcus subgroup II (Staphylococcus epidermidis biotype I) strains (Baird-Parker, 1963; 1965) has been described (van Boven, Verhoef, \& Winkler, I969; Verhoef, van Boven \& Winkler, I971 $b$, I972).

A limited number of distinct phage patterns, referred to as 'main patterns', occurred frequently (Verhoef et al. 1972). The phage patterns of the majority of the typable strains were similar or related to one of these main patterns.

With the typing phages at routine test dilution (RTD), the main patterns did not overlap. At RTD $\times 1000$ the patterns broadened considerably by the occurrence of additional weak phage reactions.

These strain differences in susceptibility are not due to differences in adsorption to subgroup II strains (Verhoef et al. I97I $b$ ). Since only a low proportion of lysogenic strains has been found among staphylococcal subgroup II strains (Verhoef, van Boven \& Winkler, I97 I $a$ ), immunity seems also to be an unlikely explanation for the differences in sensitivity.

We show that the differences in susceptibility to the phages can, for the most part be explained by host-controlled modification. Evidence is presented for the occurrence of three modification and restriction systems. A preliminary report of this study has been presented (Verhoef, van Boven \& Holtrigter, I97r).

* Present address: Laboratory of Medical Microbiology of the Free University, De Boelelaan 1117 , Amsterdam-Buitenveldert, The Netherlands. 


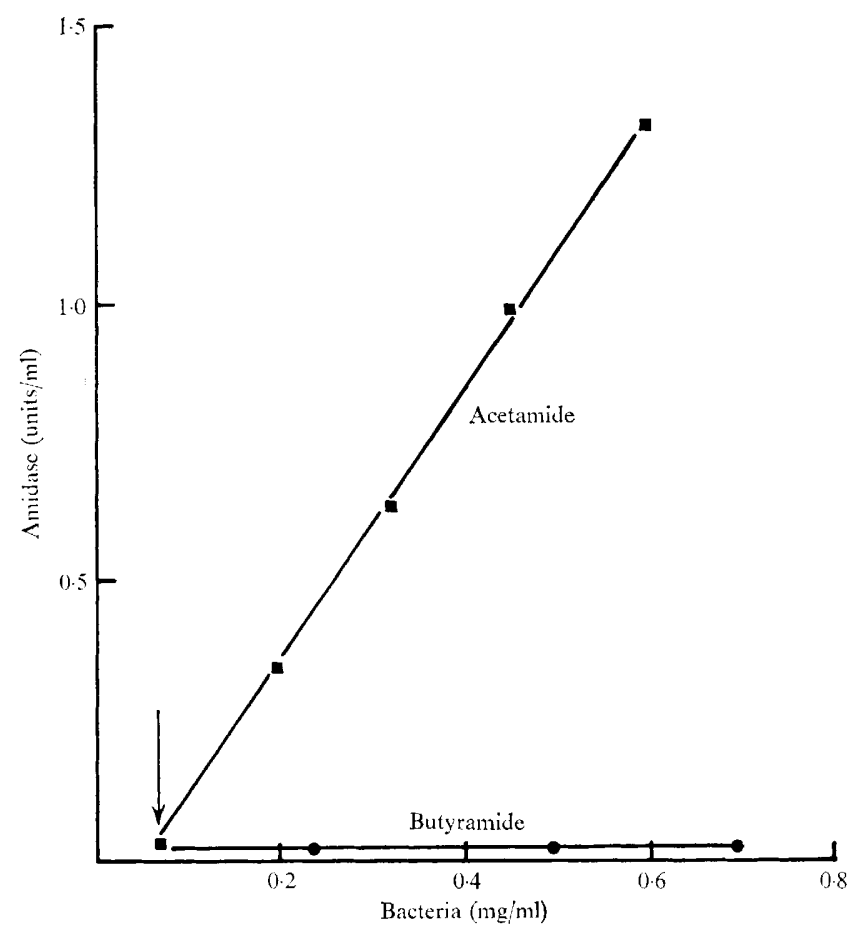

Fig. 2. Pseudomonas aeruginosa PACI. Induction of amidase synthesis in pyruvate medium. Io mM-Acetamide or --, Io mM-butyramide added at time indicated by arrow.

The rates of amidase induction in succinate medium were measured by adding formamide, acetamide, propionamide or butyramide at a concentration of $10 \mathrm{~mm}$ to exponentially growing cultures. Table 3 shows that there was no significant induction by butyramide during the experimental period. However, the rate of induction by formamide was relatively high. Table 3 includes values obtained for one of the Pseudomonas aeruginosa formamideinducible mutants which resembles $\mathrm{A} 87$ in inducer response to formamide. Formamide has a fairly high activity both as inducer and amidase substrate for $P$. putida A87 so that the relatively poor growth on $\mathrm{S} / \mathrm{F}$ plates is probably due to catabolite repression by succinate.

For $\mathrm{A} 87$ to grow on butyramide it seemed essential that butyramide should be able to induce amidase synthesis and it was thought that the lack of response in succinate medium could have been due to severe catabolic repression. A87 was grown exponentially in pyruvate medium and it was shown that amidase induction by $10 \mathrm{mM}-\mathrm{N}$-acetylacetamide was completely repressed by $10 \mathrm{~mm}$-succinate. Butyramide does not induce amidase synthesis in Pseudomonas aeruginosa PACI either in succinate medium or in pyruvate medium (Fig. 2). It does however have an effect on the induction process and when $10 \mathrm{~mm}$-butyramide was added to an exponentially growing culture already being induced by $\mathrm{N}$-acetylacetamide there was immediate and complete repression of enzyme synthesis (Fig. 3). This effect suggests that the amidase regulator protein of $P$. aeruginosa has a high affinity for butyramide but that any conformational change resulting from butyramide binding does not allow the structural gene to be released from repression. When Io mM-butyramide was added to a culture of A87 growing in pyruvate medium amidase synthesis was induced at about $10 \%$ of the acetamide rate (Fig. 4). If butyramide was added to a culture already being induced by $N$-acetylacetamide then the rate of enzyme synthesis was reduced to that which would have been obtained 


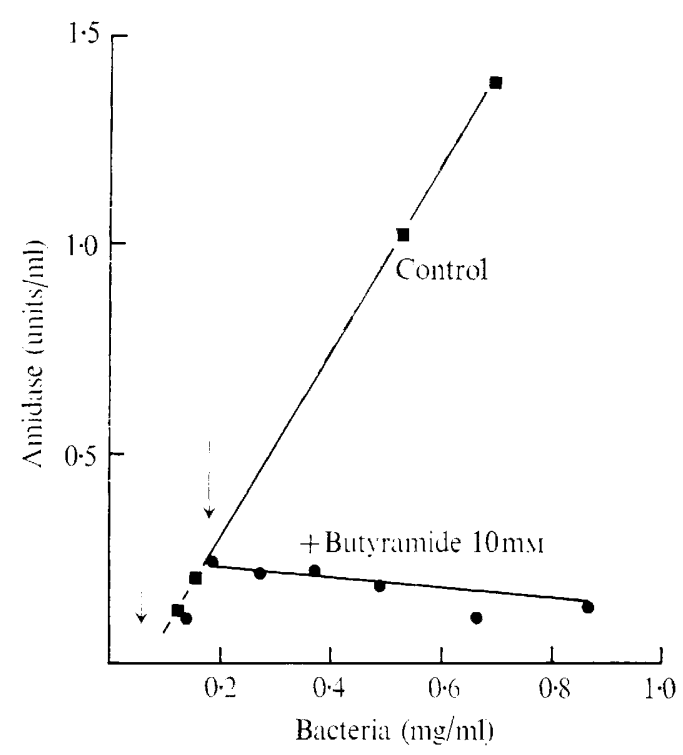

Fig. 3

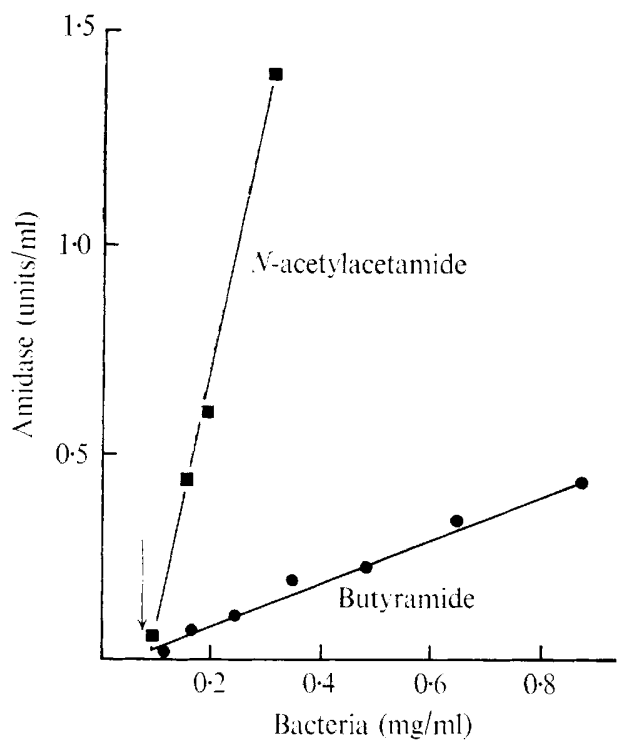

Fig. 4

Fig. 3. Pseudomonas aeruginosa PACI. Repression of amidase synthesis by butyramide. $10 \mathrm{~mm}-N$ acetylacetamide added to culture growing in pyruvate medium at time indicated by first arrow. The culture was divided into two parts at time indicated by second arrow. $\mathbf{\square}-\mathbf{n}$, Control culture; - 10 mm-butyramide added.

Fig. 4. Pseudomonas putida A87. Induction of amidase synthesis in pyruvate medium. Io mM- $N$-acetylacetamide; - - ro mM-butyramide.

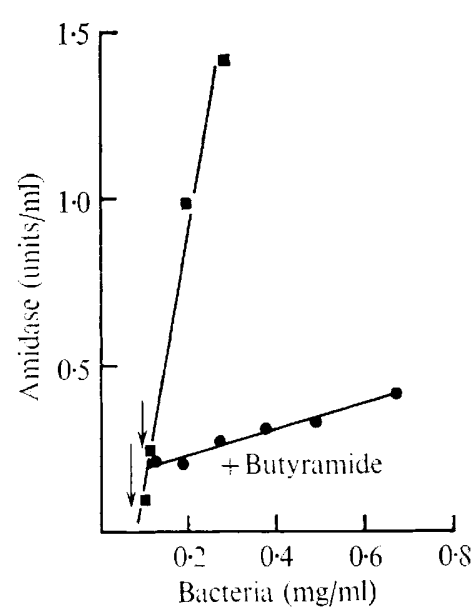

Fig. 5

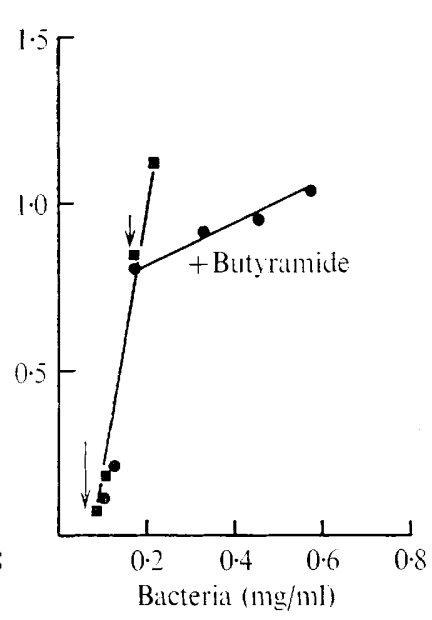

Fig. 6

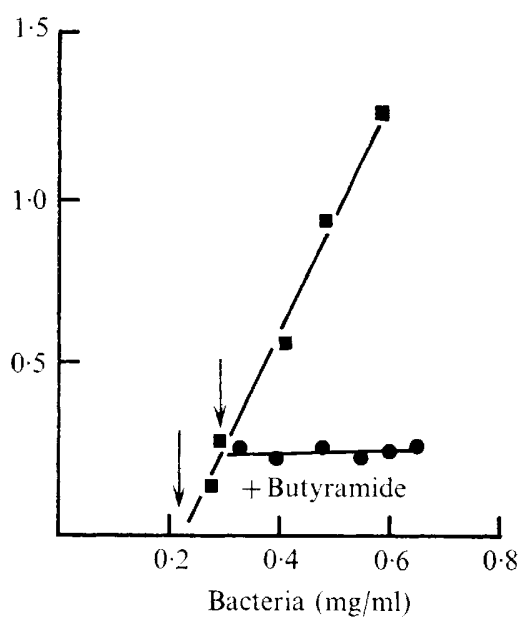

Fig. 7

Fig. 5-7. $N$-acetylacetamide (I $\mathrm{mm}$ ) added at time indicated by first arrow to cultures growing in pyruvate medium. At time indicated by second arrow the cultures were divided into two parts. --D, Control culture; - 10 mm-butyramide added.

Fig. 5, 6. Pseudomonas putida A87. Repression of amidase synthesis by butyramide.

Fig. 7. Pseudomonas acidovorans NCIB 9681. Repression of amidase synthesis by butyramide. 
Table 5. Growth of Pseudomonas species in minimal salt medium with butyramide as carbon source

\begin{tabular}{|c|c|c|c|c|c|}
\hline \multirow[t]{2}{*}{$0^{2}$} & \multicolumn{5}{|c|}{ mM-butyramide } \\
\hline & I & 10 & 25 & 75 & 100 \\
\hline \multicolumn{6}{|l|}{ Pseudomonas aeruginosa } \\
\hline PACI, PACI I I & - & - & - & - & - \\
\hline PACI 28 & - & ++ & +++ & $+t+$ & + \\
\hline PACI 35 & + & ++ & $+t+$ & +++ & $++t$ \\
\hline 277 & - & - & - & - & - \\
\hline \multicolumn{6}{|l|}{ P. putida } \\
\hline A5I, A56, A76 & - & - & - & - & - \\
\hline AI 54 & - & ++ & ++ & ++ & ++ \\
\hline A87 & - & + & + & ++ & ++ \\
\hline $\mathrm{A} 87 \mathrm{CI}$ & - & ++ & ++ & ++ & ++ \\
\hline \multicolumn{6}{|l|}{ P. acidovorans } \\
\hline NCIB 968I & + & + & ++ & + & - \\
\hline 14 & - & ++ & $+t+$ & +++ & +++ \\
\hline $6 I$ & - & + & + & ++ & ++ \\
\hline 105 & - & ++ & $++t$ & ++ & ++ \\
\hline 114 & - & - & - & - & - \\
\hline \multicolumn{6}{|l|}{$P$. cepacia } \\
\hline $714,716,727,738,744$ & - & - & - & - & - \\
\hline
\end{tabular}

Growth is expressed as follows: $E_{670 \mathrm{~nm}}<0 \cdot \mathrm{I}=-; 0 \cdot \mathrm{I}-0.5=+; 0.5-\mathrm{I} \cdot 0=++;>\mathrm{I} \cdot 0=+++$.

if butyramide had been added by itself. It appeared to make very little difference whether the butyramide was added fairly soon after the $N$-acetylacetamide or after amidase synthesis had become well established (Fig. 5, 6).

The growth of A87 and AI54 on butyramide plates seemed therefore to depend on the induction of an amidase with a relatively low activity towards butyramide. A87 and AI54 also grew in minimal salt medium containing various concentrations of butyramide but A5I, A56 and A76 were unable to do so (Table 5). Cultures of these strains were used to inoculate patch plates of butyramide medium by spreading a loopful of a bacterial suspension on a small area of the agar. A87 and AI54 produced heavy growth after 2 to 3 days and after 7 days mutant colonies could be seen in the faint background growth of the patches of strains A5I, A56 and A76. Eight of the butyramide-utilizing mutants were tested by the plate microtest method and all were found to be constitutive for amidase production.

It was concluded that the acetamide-positive Pseudomonas putida A strains produced amidases with similar properties and that they differed in regulatory response to butyramide. A5I, A56 and A76 resembled the wild-type $P$. aeruginosa PACI and were not induced by butyramide. The butyramide-utilizing mutants isolated from these strains resembled the group of amidase regulatory mutants isolated by Brown \& Clarke (I970). A87 and AI 54 differed in being butyramide-inducible and, although it would have been theoretically possible, none of the butyramide-utilizing mutants isolated from PAC strains have had this property. The $P$. putida strains can be divided into those with functional amidase structural genes with an acetamide-positive phenotype, and those in which the amidase genes are non-functional (or totally lacking) with an acetamide-negative phenotype. The acetamide-positive group can be subdivided into those which are inducible by acetamide and not by butyramide and those which are inducible by acetamide and butyramide and grow on both amides. Two acetamidenegative $P$. putida A strains, A90 and AI30, were tested to see if acetamide-positive mutants could be isolated. Bacteria $\left(2 \times 10^{9}\right)$ were spread on acetamide plates and incubated at $30^{\circ} \mathrm{C}$ 
for Io days. Mutants did not appear from untreated cultures or from a culture treated with $N$-methyl- $N^{\prime}$-nitro- $N$-nitrosoguanidine (Brown et al. 1969). A cell-free extract was prepared from A90 grown overnight in lactate medium containing $0.02 \%(\mathrm{w} / \mathrm{v})$ lactamide. No cross reacting material was detected in the immunodiffusion test with antiserum to $P$. aeruginosa A amidase.

\section{Pseudomonas acidovorans amidase}

The amidases produced by the Pseudomonas acidovorans strains were also inducible. These strains grew much more slowly than $P$. aeruginosa and $P$. putida in acetamide or acetate minimal salt medium. After 3 days at $30^{\circ} \mathrm{C}$ the cultures had grown sufficiently to be harvested, reaching $E_{670 \mathrm{~mm}} \mathrm{I} \cdot \mathrm{O}$ to I. 7 for most cultures. The amidase specific activities of strains I 4 and NCIB 968I usually reached a value of I I to 16 after 3 days of growth but the specific activities of the other strains were about $2 \cdot 0$ after this growth period. Growth with other carbon sources, e.g. succinate or lactate, was at about the same rate as that for $P$. putida so that the growth rate-limiting step in acetamide medium might have been due to a slow rate of utilization.

The immunodiffusion tests showed strong cross-reactions between the amidases in the extracts of acetamide-grown cultures of Pseudomonas acidovorans strains I4 and NCIB $968 \mathrm{I}$ with the antiserum to $P$. aeruginosa A amidase. Heavy spurring occurred with both $P$. putida and $P$. aeruginosa amidases indicating that the $P$. acidovorans enzyme has incomplete homology, but nevertheless some resemblance, to the amidases of both species (Fig. I). No reactions were detected with extracts from succinate-grown cultures.

Cell-free extracts of strains 14 and $\mathrm{NCIB} 968 \mathrm{I}$ were subjected to starch gel electrophoresis. The overall protein pattern was the same for the two extracts and markedly different from that observed for the other species. The amidase bands of strain 14 and NCIB 968I were in the same position and the enzyme ran slightly behind the Pseudomonas aeruginosa A amidase and slightly ahead of the P. aeruginosa B amidase. The differences in electrophoretic mobilities were not great but identical results were obtained with extracts prepared from several batches of strain NCIB 968I. Extracts of NCIB 968I which had been stored at $4{ }^{\circ} \mathrm{C}$ for a few days gave only weak and diffuse bands on starch gels with the general protein stain although amidase activity could still be detected with the specific amidase stain. This suggested that the extracts contained very active proteolytic enzymes which attack the proteins in cell-free extracts.

Transferase activities for substrate specificity were carried out with a washed suspension of NCIB 968I and a cell-free extract of strain I4. There were no significant differences between the values obtained. The acetamide: propionamide ratio was $100: 26$ and the relative value for butyramide was 0.5 . Hydrolase activities were measured with a washed suspension of NCIB 968I. The relative rate for butyramide hydrolysis was no greater than that measured for Pseudomonas putida but the rate of propionamide hydrolysis was relatively lower (Table 4).

Strains 14, 6I, 105 and $\mathrm{NCIB} 968 \mathrm{I}$ grew on butyramide plates and in liquid minimal salt medium with butyramide as the carbon source. Strain II4 did not grow in these media (Table 5). It was expected that butyramide would induce amidase synthesis in pyruvate medium in much the same way as with the Pseudomonas putida strains. However, only a trace of amidase activity could be detected during $4 \mathrm{~h}$ of exponential growth of NCIB 968I in pyruvate medium containing $10 \mathrm{~mm}$-butyramide. Moreover, when $10 \mathrm{~mm}$-butyramide was added to a culture being induced with Io mM- $N$-acetylacetamide the synthesis of amidase was immediately and completely repressed (Fig. 7). For growth to occur in butyramide 
medium it was obviously essential that amidase should be induced and the difference between $P$. acidovorans and $P$. putida proved to be in the time taken for butyramide to induce significant amounts of enzyme. Cultures of NCIB 968I and strain I4 grown overnight in succinate or pyruvate medium containing $10 \mathrm{~mm}$-butyramide had amidase specific activities of about half of those for cultures induced with acetamide in the same medium. Both these amides can be used as substrates but acetamide is attacked much more readily than butyramide, so that the effective amide concentrations after this period of growth may differ considerably.

The Pseudomonas acidovorans amidase appears to be fairly similar to the $P$. aeruginosa and $P$. putida enzymes in range of aliphatic amides hydrolysed although the enzyme proteins are clearly distinguishable by their electrophoretic and immunological properties. The amidases of the $P$. acidovorans strains examined, with the exception of 1 I 4 , would appear to have regulatory properties resembling those of $P$. putida A87. The slower response to butyramide induction may have been due to differences in the characteristics of the regulator genes or to the generally slower growth of the $P$. acidovorans strains in the media used.

\section{Pseudomonas cepacia amidase}

The Pseudomonas cepacia strains grew well in acetamide minimal salt medium but the amidase specific activities of strains 716 and 727 were rather low and varied between 3 and 6 after $24 \mathrm{~h}$ growth. No amidase activity could be detected after growth in succinate medium. Cell-free extracts of the two cultures grown on acetamide gave a clear pattern of protein bands after electrophoresis on starch gels and the pattern was again distinct from that of the other Pseudomonas species. The amidase activity detected by the transferase reaction with acetamide as substrate appeared as a single band. The position of the 716 and 727 amidase bands were identical and the $P$. cepacia amidase ran just behind the $P$. acidovorans amidase. Although the concentrated extracts had good amidase activity it was difficult to detect any precipitin lines in the immunodiffusion tests against the antiserum to $P$. aeruginosa A amidase. By heavily loading the gels with the cell extract ( $30 \mu \mathrm{l}$ of extract) it was possible to see very faint precipitin bands and to detect spurring with $P$. aeruginosa, $P$. putida and $P$. acidovorans amidases. These reactions were considered to be valid since they could only be obtained with acetamide-grown cultures and no precipitin bands could be detected with extracts of succinate-grown cultures (Fig. I). The results suggest that there are many differences between the proteins of the amidases produced by $P$. cepacia and the other three species.

The relative transferase activities were measured with cell-free extracts from 716 and 727 . The acetamide:propionamide:butyramide ratio was 100:22:0.5 and therefore similar to that of the Pseudomonas acidovorans, P. putida and $P$. aeruginosa enzymes. The relative hydrolase activities were measured with a washed suspension of strain 716 (Table 4 ). The substrate profile was not markedly different from that of the amidases of the wild-type strains of the other species.

None of the Pseudomonas cepacia cultures grew on butyramide plates, there was no growth in butyramide minimal salt medium and no amidase was detected after cultures had been grown overnight in pyruvate medium containing $10 \mathrm{~mm}$-butyramide. The inability of these strains to utilize butyramide for growth is probably due to the absence of induction by butyramide since the substrate specificity of the enzyme was very similar to that of the other species examined. 


\section{DISCUSSION}

The aliphatic amidases produced by strains of Pseudomonas aeruginosa, P. putida, $P$. acidovorans and $P$. cepacia proved to be inducible enzymes with very similar substrate specificities. The main differences between these strains with respect to growth on amides appeared to be in the regulation of amidase synthesis. Some strains of $P$. putida and $P$. acidovorans were able to grow on butyramide and in these cases butyramide was a reasonably effective inducer. Pseudomonas acidovorans and $P$. cepacia strains grew much better on the succinate + formamide medium than did the $P$. aeruginosa strains, and the $P$. putida strains grew slightly better. The factors determining growth on this medium include inducer and substrate specificities and catabolite repression; slight differences in the balance of these factors will be sufficient to account for differences in growth. The $P$. aeruginosa strains were very similar with respect to growth on the test amides and also to inducer and substrate specificities. There was more variation among the strains of the other species, but none of the acetamide-negative strains grew on any of the other test amides. Thus, for classification purposes it can probably be inferred that absence of growth on acetamide means that the strain lacks an aliphatic amidase.

The results of the starch gel electrophoresis experiments indicated that there were only very slight differences between the electrophoretic mobilities of the amidases produced by the 4 species. Much greater differences had previously been observed between the wild-type PACI amidase and the B and AI amidases produced by mutants of this strain (Brown et al. I969; Brown \& Clarke, I972).

The immunodiffusion experiments would suggest that the amidases of the Pseudomonas aeruginosa strains have a very high degree of antigenic homology. This would confirm the previous observations on the biochemical uniformity of this species (Stanier et al. 1966). There appeared to be partial antigenic homology between the amidases of $P$. aeruginosa and the $P$. putida biotype A strains. This fits in with the similar finding for two of the $\beta$-ketoadipate pathway enzymes (Stanier, 1968). Rather surprisingly, the $P$. acidovorans amidase also gave strong cross-reactions with the $P$. aeruginosa antiserum in a way that suggested some homology with both the $P$. aeruginosa and $P$. putida enzymes. The $P$. cepacia amidase appeared to be antigenically very different from the enzymes produced by the other three species.

We have shown (Brammer et al. 1967) that the Pseudomonas aeruginosa amidase is determined by two closely linked genes; the amidase structural gene and the amidase regulator gene. We have been able to produce mutants of strain PACI which have an increased range of amides available as growth substrates by making mutations in either the regulator gene or the structural gene. Some of these mutants can be compared with the wild-type strains of the other species. It seems likely that the two amidase genes had a common origin and evolved first by gene duplication and then by independent mutation to give the growth characteristics and enzyme properties we can now recognize. The differences which occur in amidase regulation of the four Pseudomonas species indicate species divergence of the amidase regulator gene. The enzyme properties have remained remarkably similar, but the antigenic reactions suggest that the amidase structural genes of $P$. aeruginosa, $P$. putida and $P$. acidovorans have more resemblance to each other than to the amidase structural gene of $P$. cepacia. However, it has recently been found that genetic transfer may occur between Pseudomonas species. Chakrabarty \& Gunsalus (1970) were able to transduce genes between $P$. putida and $P$. aeruginosa with phage pf 20 . The genes for camphor metabolism were shown to be carried on a plasmid which can be transmitted to other strains of $P$. putida and also to 
$P$. aeruginosa, thereby enabling them to produce the camphor pathway enzymes (Rheinwald, Chakrabarty \& Gunsalus, 1972). Stanisich \& Holloway (1971) showed that some plasmids determining drug resistance could act as sex factors in $P$. aeruginosa and transfer chromosomal genes. We have shown that several of these drug resistance factors can be transferred from $P$. aeruginosa to P. putida (P. H. Clarke, unpublished). It is therefore necessary to be cautious in interpreting similarities in protein properties of catabolic enzymes of pseudomonads to long standing evolutionary relationships, since they may have exchanged the relevant genes in relatively recent times by interspecies genetic transfer.

I am grateful to Mr P. D. Laverack for valuable assistance during this investigation.

\section{REFERENCES}

Ballard, R. W., Palleroni, N. J., Doudoroff, M. \& Stanier, R. Y. (1970). Taxonomy of the aerobic pseudomonads: Pseudomonas cepacia, P. marginata, P. allicola and P. caryophylli. Journal of General Microbiology 60, I19-214.

Brammar, W. J. \& Clarke, P. H. (1964). Induction and repression of Pseudomonas aeruginosa amidase. Journal of General Microbiology 37, 307-319.

Brammar, W. J., Clarke, P. H. \& Skinner, A. J. (1967). Biochemical and genetic studies with regulator mutants of the Pseudomonas aeruginosa 8602 amidase system. Journal of General Microbiology 47, $87-102$.

Brown, J. E., Brown, P. R. \& Clarke, P. H. (I969). Butyramide-utilizing mutants of Pseudomonas aeruginosa 8602 which produce an amidase with altered substrate specificity. Journal of General Microbiology 57, $273-285$.

Brown, J. E. \& Clarke, P. H. (I970). Mutations in a regulator gene allowing Pseudomonas aeruginosa 8602 to grow on butyramide. Journal of General Microbiology 64, 329-342.

Brown, P. R. \& Clarke, P. H. (1972). Amino acid substitution in an amidase produced by an acetanilideutilizing mutant of Pseudomonas aeruginosa. Journal of General Microbiology (in the press).

Buhlmann, X., Vischer, W. A. \& BruHin, H. (I96I). Identification of apyocyanogenic strains of Pseudomonas aeruginosa. Journal of Bacteriology 82, 787-788.

Chakrabarty, A. M. \& Gunsalus, I. C. (1970). Transduction and genetic homology between Pseudomonas species putida and aeruginosa. Journal of Bacteriology 103, 830-832.

Clarke, P. H. (1970). The aliphatic amidases of Pseudomonas aeruginosa. Advances in Microbial Physiology 4, $179-222$.

Clarke, P. H., Houldsworth, M. A. \& Lilly, M. D. (1968). Catabolite repression and the induction of amidase synthesis by Pseudomonas aeruginosa 8602 in continuous culture. Journal of General Microbiology 51, 225-234.

Demerec, M., Adelberg, A. E., Clark, A. J. \& Hartman, P. E. (i966). A proposal for a uniform nomenclature in bacterial genetics. Genetics 54, 6I-76.

Gammack, D. B., Huehns, E. R., Shooter, E. M. \& Gerald, P. (1960). Identification of the abnormal chain of haemoglobin $\mathrm{G}_{1 \mathrm{~b}}$. Journal of Molecular Biology 2, 372-378.

Holloway, B. H. (1969). Genetics of Pseudomonas. Bacteriological Reviews 33, 4I9-443.

JAKOBY, W. B. \& FREDERICKS, J. (I964). Reactions catalysed by amidases. Acetamidase. Journal of Biological Chemistry 239, 1978-1982.

Kelly, M. \& Clarke, P. H. (1960). Amidase production by Pseudomonas aeruginosa. Biochemical Journal 74, $21 \mathrm{P}$.

Kelly, M. \& Clarke, P. H. (1962). An inducible amidase produced by a strain of Pseudomonas aeruginosa. Journal of General Microbiology 27, 305-3I 6.

Kelly, M. \& Kornberg, H. L. (1964). Purification and properties of acyltransferases from Pseudomonas aeruginosa. Biochemical Journal 93, 557-566.

Kemp, M. B. \& Hegeman, G. D. (I968). Genetic control of the $\beta$-keto adipate pathway in Pseudomonas aeruginosa. Journal of Bacteriology 96, I488-1499.

Ornston, L. N. (1966). The conversion of catechol and protocatechuate to $\beta$-ketoadipate by Pseudomonas putida. III. Enzymes of the catechol pathway. Journal of Biological Chemistry 241, 3795-3799. 
Queener, S. F. \& Gunsalus, I. C. (1970). Anthranilate synthase enzyme system and complementation in Pseudomonas species. Proceedings of the National Academy of Sciences of the United States of America 67, $1225-1232$.

Rheinwald, J. G., Chakrabarty, A. M. \& Gunsalus, I. C. (1972). A transmissible plasmid controlling camphor degradation in Pseudomonas putida (in the press).

Rosenberg, S. L. \& Hegeman, G. D. (1969). Clustering of functionally related genes in Pseudomonas aeruginosa. Journal of Bacteriology 99, 353-355.

Stanier, R. Y. (1968). Biochemical and immunological studies on the evolution of a metabolic pathway in bacteria. In Chemotaxonomy and Serotaxonomy, pp. 201-225. Edited by J. G. Hawkes. London: Academic Press.

Stanier, R. Y., Palleroni, N. J. \& Doudoroff, M. (I966). The aerobic pseudomonads: a taxonomic study. Journal of General Microbiology 43, I 59-271.

Stanisich, V. A. \& Holloway, B. W. (1971). Chromosome transfer in Pseudomonas aeruginosa mediated by $\mathrm{R}$ factors. Genetical Research, Cambridge I7, I69-172. 